\title{
El descubrimiento de la primera traducción impresa en ladino de Pirqué Abot (Salónica, hacia 1570)
}

\author{
Ora (Rodrigue) Schwarzwald* \\ Bar-Ilan University (Israel) \\ ORCID ID: https://orcid.org/0000-0001-9653-6958 \\ Dov Cohen** \\ Bar-Ilan University (Israel) \\ ORCID ID: https://orcid.org/0000-0001-6549-2948
}

Entre 1552 y 1965 se publicaron muchas traducciones de Pirqué Abot ('Tratado de los Padres') en ladino, en caracteres hebreos o latinos, en las ciudades del Imperio otomano, denominadas orientales, así como en las ciudades de Italia, Ámsterdam y Londres, consideradas occidentales. La primera traducción aljamiada conocida es la versión de Venecia de 1601, publicada por la imprenta de Giovanni di Gara. Investigaciones anteriores han demostrado que la versión de Venecia de 1601 se asemeja mucho más a las versiones posteriores publicadas en el Imperio otomano, especialmente en Salónica, que a las publicadas en Italia, Ámsterdam y Londres. Recientemente se ha rescatado, entre los documentos de la Guenizá de El Cairo, una versión de Pirqué Abot publicada hacia 1570 en la imprenta de Yosef Yaabets en Salónica. Al comparar la versión de 1601 con la recientemente descubierta, se observa que no sólo son casi idénticas, sino que de hecho la versión de Venecia se basa en la versión de Salónica. Otros textos publicados en Venecia en el mismo período corroboran esta conclusión. Esta edición en ladino es ahora considerada como la más antigua que se conoce.

Palabras Clave: Bibliografia hebrea; léxico; Giovanni di Gara; Guenizá de El Cairo; Imperio Otomano; judeoespañol; traducciones en ladino.

The Discovery of the First Printed Translation into Ladino of Pirkey Avot (ThessalONIKI, CA. 1570).- Between 1552 and 1965, numerous Ladino translations of Pirkey Avot ("Ethics of the Fathers") were published using either Hebrew or Latin characters at various locations throughout the Ottoman Empire as well as in Italy, Amsterdam and London. The first known printed Ladino translation using Hebrew characters was published in 1601 at Giovanni di Gara's printing house in Venice. Previous research has proven that this Venice translation more strongly resembles later translations originating

*ora.schwarzwald@biu.ac.il

**dov.cohen@biu.ac.il

Copyright: (C) 2020 CSIC. Este es un artículo de acceso abierto distribuido bajo los términos de la licencia de uso y distribución Creative Commons Reconocimiento $4.0 \mathrm{In}$ ternacional (CC BY 4.0). 
from Eastern Mediterranean diaspora communities, especially Thessaloniki, than it does those published in the Italy, Amsterdam or London. A version of a Ladino translation of Pirkey Avot from Thessaloniki ca. 1570 has recently been discovered among remnants of the Cairo Genizah in Cambridge. A comparison of the 1601 and 1570 versions shows that not only are they very similar, but that it is also evident that the 1601 version is based on the Thessaloniki translation $c a$. 1570. Other texts published in Venice at the same printing house support this conclusion. This edition is now considered the oldest known version published in Ladino.

Keywords: Jewish Bibliography; Lexicon; Giovanni di Gara; Cairo Genizah; Ottoman Empire; Judeo-Spanish; Ladino translations.

\section{INTRODUCCIÓN}

Pirqué Abot ('Tratado de los Padres') es uno de los tratados más populares y conocidos de la Mišná. A diferencia de otros que son, principalmente, discusiones halájicas, la singularidad de Pirqué Abot radica en el hecho de que versa sobre el comportamiento respetuoso, la ética y las virtudes, e incluye dichos de los sabios del período de la Mišná que expresan sabiduría y consejos para el buen comportamiento en general y el comportamiento cotidiano de conformidad con las leyes del judaísmo en particular. Pirqué Abot es considerado también un texto litúrgico y por ello los judíos sefardíes leen los seis capítulos de este tratado los sábados entre Pésah (Pascua) y Šabu'ot (Pentecostés), un capítulo cada semana ${ }^{1}$, mientras que los judíos asquenazíes leen parte de los capítulos los sábados desde Pésạ̣ hasta Roš Hašaná (Año Nuevo).

A lo largo del tiempo, Pirqué Abot ha sido objeto de numerosas publicaciones y traducido a diversas lenguas, incluidas las lenguas judías, para que aquellos que no entienden hebreo puedan también aprender de este texto ${ }^{2}$. Pirqué Abot ha sido traducido al ladino y al español en muchas ocasiones, desde la Edad Media hasta el presente. Las traduc-

${ }^{1}$ En sus orígenes, este tratado contenía solo cinco capítulos; el sexto fue agregado en un período posterior, por el deseo de proporcionar material de lectura para esos seis sábados.

2 Para una bibliografía amplia, cf. Steven J. Weiss, Pirke Avot: A Thesaurus: An Annoted Bibliography of Printed Hebrew Commentaries 1485-2015 (Los Angeles-Jerusalem: Keter, 2016 [en hebreo]). 
ciones medievales conservadas en manuscritos del siglo XV están escritas en caracteres latinos. Gutwirth encontró en la Guenizá de El Cairo un fragmento de un manuscrito español que incluye algunos pasajes del capítulo $4^{3}$, Lazar incluyó en su edicion del Séfer Těsubá de la Biblioteca Universitaria de Salamanca una traducción exegética española completa de Pirqué Abot ${ }^{4}$, y Sainz de la Maza analizó el manuscrito incompleto de Pirqué Abot de la Biblioteca Nacional de Madrid ${ }^{5}$. Estas tres traducciones reflejan el español peninsular de su tiempo y no son fieles al texto hebreo. Si bien es cierto que algunas de las diferencias refejan las distintas variantes existentes en la tradición textual hebrea ${ }^{6}$, la gramática y el léxico sugieren que se trata de traducciones libres ${ }^{7}$.

Después de la Edad Media, se editaron traducciones de Pirqué Abot al ladino en caracteres hebreos y latinos en numerosas ciudades: Ámsterdam, Belgrado, Esmirna, Estambul, Ferrara, Florencia, Livorno, Londres, Nueva York, Pisa, Salónica, Tel Aviv, Venecia y Viena ${ }^{8}$. Las

${ }^{3}$ Identificado como T-A AS 209.256, empieza en la mitad de la Mišná a) del capítulo 4 y termina en la Mišná $f$ ). El texto está muy fragmentado, pero difiere esencialmente de las traducciones al ladino difundidas después de la expulsión de España; $c f$. Eleazar Gutwirth, «A Medieval Spanish Translation of Avot: Geniza Fragments», Annali 49:3 (1989) págs. 289-300.

${ }^{4}$ Identificado como Ms. 2015; cf. Moshe Lazar, (ed.), Sēfer Tešuḅāh: A Ladino Compendium of Jewish Law and Ethics (Culver City: Labyrinthos, 1993) págs. 63-81. Véase también Francisco Márquez Villanueva, «Sobre el concepto de judaizante», en De la España judeoconversa. Doce estudios (Barcelona: Bellaterra, 2006) págs. 95-114.

5 Identificado como Ms. 5644; $c f$. Carlos SAINZ DE la MAZA, «Abot de los conversos hacia 1450», eHumanista / Conversos 1 (2013) págs. 86-104.

${ }^{6}$ Cf. Shimon Sharvit, Language and Style of Tractate Avoth through the Ages (Beer Sheva: Ben Gurion University, 2004 [en hebreo]) págs. 11-17 y 60-124, y Tractate Avoth through the Ages (Jerusalem: The Bialik Institute, 2006 [en hebreo]) págs. 15-37. Más adelante se presentarán más ejemplos de esta inconsistencia.

${ }^{7}$ Por ejemplo: la $r$ se duplica al principio de algunas palabras antes de una vocal; en todas las oraciones nominales hay un verbo copulativo, ser; no se usan formas abreviadas del participio presente como dićién, sino solo verbos indicativos, como dice; la palabra española Dios aparece en lugar de el Dio en judeoespañol y en todas las traducciones del ladino después de la expulsión; en lugar de amyeźar (enseñar, avisar), común en judeoespañol y en las traducciones en ladino, aparece el verbo aprender o mostrar, etc.

8 Cf. Ora (Rodrigue) Schwarzwald, The Ladino Translations of Pirke Aboth (=Eda VeLashon 13 [Jerusalem: Magnes, 1989. En hebreo]). Las versiones de Esmirna, de Estambul y de Nueva York no se incluyeron en este libro. 
traducciones de Ferrara, Ámsterdam y Londres, que fueron impresas en caracteres latinos, a veces sin el texto hebreo, destinadas a las comunidades de los conversos que retornaban al judaísmo y a sus descendientes, son las más tempranas, desde 1552 (Ferrara) hasta 1867 (Ámsterdam). En las ciudades italianas de Venecia y Florencia se publicaron traducciones tanto en caracteres hebreos como latinos, desde 1601 a 1780. A partir de 1800 todas las demás traducciones publicadas en el Imperio otomano y en Italia (Pisa y Livorno) se imprimieron en caracteres hebreos. Todas las traducciones al ladino se ajustan al texto hebreo y a su sintaxis, a diferencia de las traducciones medievales al español, que son traducciones libres.

La primera edición de una traducción de Pirqué Abot al ladino impresa en caracteres hebreos conocida hasta la fecha fue publicada en 1601 en Venecia, Italia, por Giovanni di Gara ${ }^{9}$. En el único ejemplar que conocemos de esta edición falta la portada ${ }^{10}$. La identidad del impresor se deduce del examen tipográfico y la comparación del tipo de letras con las utilizadas en la imprenta de Giovanni di Gara. La fecha de impresión aparece en la última página: 9 de la cuenta del 'ómer de 5361 (26 de abril de 1601). El libro contiene 42 hojas numeradas con letras. La Mišná está dividida en seis capítulos, las mišnayot no están numeradas, de manera similar a todas las impresiones investigadas en ladino, pero en la parte superior de cada página aparece el número del capítulo correspondiente: capítulo primero, capítulo segundo, etc., hasta el capítulo sexto ${ }^{11}$. Tanto el texto original en hebreo como la traducción al ladino están escritos en caracteres hebreos vocalizados, siendo el texto en hebreo impreso con letras ligeramente más grandes que el texto en ladino ${ }^{12}$.

9 Abraham Meir Habermann, Giovanni di Gara, Printer, Venice 1564-1610 (Jerusalem: Habermann Institute for Literary Research, 1982 [en hebreo]) pág. 102. Se conoce un solo ejemplar de esta edición, que se encuentra en la biblioteca del Seminario Rabínico de Cincinnati, de la cual hemos recibido una copia del libro en microfilme (microfilme no. A422 5783). Otra copia en microfilme se conserva en la biblioteca del Instituto Ben Zvi en Jerusalén (signatura L-200).

${ }^{10}$ El libro empieza en la pág. 2.

${ }^{11}$ En la pág. 32b dice por error capítulo cuatro en lugar de cinco, en la pág. 33b dice por error capitulo tres en lugar de cinco y en la pág. 37a dice capitulo cinco en lugar de seis.

12 Falta la Mišná inicial tomada de Sanhedrin 10a, que en otras traducciones en ladino aparece antes del capítulo 1a. 
Los estudios de Schwarzwald sobre las cuarenta y seis ediciones de Pirqué Abot han demostrado, sin lugar a dudas, que la edición de 1601 es singular: el léxico del ladino utilizado en ella difiere del que aparece en las ediciones posteriores de Venecia en caracteres hebreos, de 1696, 1729,1739 y 1780 , pero en muchos aspectos se parece a las ediciones del Imperio otomano (en adelante, ediciones orientales), especialmente las de Salónica. Por esta razón, fue clasificada a medio camino entre las ediciones del Imperio otomano que fueron publicadas posteriormente, y las ediciones occidentales de Italia, los Países Bajos e Inglaterra, publicadas antes de $1800^{13}$.

\subsection{Pirqué Abot en la Guenizá de El Cairo}

En nuestra reciente revisión de los fragmentos de la Guenizá de El Cairo conservados en la biblioteca de la Universidad de Cambridge, hemos encontrado fragmentos de diversas ediciones de Pirqué Abot con traducción al ladino ${ }^{14}$. Debido a la condición fragmentaria de estos restos, desde fragmentos de una página hasta unas pocas hojas, no siempre es posible identificar los datos bibliográficos exactos de cada uno de ellos y determinar a qué edición pertenece cada fragmento. Excepto en casos aislados en los que afortunadamente se conserva un fragmento con detalles identificatorios claros ${ }^{15}$, en la mayoría de los casos la identificación solo es posible tras un meticuloso examen de todas las características tipográficas de los fragmentos y la comparación con otras ediciones y libros cuya identificación es clara. Entre los fragmentos de las ediciones de Pirqué Abot con traducción al ladino

13 Schwarzwald, Translations, págs. 74-96, y Ora (Rodrigue) Schwarzwald, "The Venice 1601 Ladino Translation of Pirke Aboth», Folia Linguistica Historica 11:1-2 (1990 [1992]) págs. 131-145.

14 Para una reseña de los resultados del examen de ediciones en ladino de la Guenizá de El Cairo, $c f$. Dov CoHen, «Missing Treasures: Tracking Lost Ladino Books», Zutot 17 (2020) págs. 58-73.

15 Así, por ejemplo, hemos descubierto en la Guenizá la portada de Pirqué Abot, edición de Salónica 1870 (CUL T-S Misc. 34.11). 
que encontramos en la Guenizá se hallan algunos impresos en los siglos XVI a XIX ${ }^{16}$.

En el presente artículo nos centraremos en una edición de Pirqué Abot del siglo XVI con traducción al ladino, de la cual encontramos 18 hojas (36 páginas) dispersas en diferentes colecciones de la Guenizá ${ }^{17}$. Esta edición, que no había sido documentada en ninguna fuente anterior, es probablemente la primera traducción aljamiada de Pirqué Abot en ladino. La tipografía es idéntica a la de otros libros impresos por Yosef Yaabets en Salónica entre 1565-1571 ${ }^{18}$, por lo que suponemos que también esta edición fue publicada hacia 1570 en la misma imprenta. A continuación se presenta una breve descripción de las páginas y fragmentos recientemente descubiertos.

\subsection{Pirqué Abot de Salónica, hacia 1570}

Tanto el original en hebreo como la traducción fueron escritos en caracteres hebreos vocalizados, la Mišná en hebreo y a continuación la traducción en letras ligeramente más pequeñas. El tamaño de las hojas es de 11 x 7 cms. Las mišnayot de las hojas encontradas no están numeradas ${ }^{19}$, y algunos fragmentos están descoloridos; en la parte superior de cada página aparece el número del capítulo. En los cuatro primeros aparece el número ordinal: capítulo primero, capítulo segundo ${ }^{20}$, capítulo cuarto. En los dos últimos aparece el número cardinal: capítulo cinco y capítulo seis. Las 18 hojas descubiertas no están numeradas. Sin

16 Para los fragmentos del siglo XVII, $c f$ : CUL T-S NS 30.54. Para los del siglo XVIII, $c f:$ : CUL T-S AS 191.460; CUL T-S NS 25.116; CUL T-S NS 25.165; CUL T-S NS 191.2. Para los del siglo XIX, $c f:$ CUL T-S NS 267.54; CUL T-S Misc. 34.11.

17 CUL T-S Misc. 15.26; CUL T-S Misc. 15.57; CUL T-S Misc. 34.14; CUL T-S NS 25.16; CUL T-S NS 25.117; CUL T-S NS 25.174; CUL T-S NS 26.198; CUL T-S NS 27.363; CUL T-S NS 28.127; CUL T-S NS 29.109; CUL T-S NS 30.7; CUL T-S NS 165.187; CUL T-S AS 190.170.

18 Por ejemplo Séder Našim (hacia 1565), Meśa de el alma (hacia 1568) e Iyob ve-Daniel be-lá aź (1571).

19 Las mišnayot están numeradas a continuación aquí como es habitual hoy en día en los textos impresos, con indicación de los incisos de las mišnayot.

20 Falta el capítulo 3, con excepción del final; véase más abajo. 
embargo los cuadernos sí están numerados con letras. En las hojas que se han conservado, encontramos solo la numeración de los cuadernos 2 , 9 y 10: el cuaderno bet $\langle$ ב $>$ [=2], al final del primer capítulo, el tet $\langle 0\rangle$ [=9], en la mitad del capítulo 5 y el yod $<>>[=10]$, en la mitad del capítulo 6. Como las hojas descubiertas estaban dispersas en las colecciones de la Guenizá, no se conservaron en el orden correspondiente y por eso hemos tratado de ordenarlas.

Los fragmentos descubiertos son los siguientes:

Capítulo 1 (una página y un tercio):

Desde el final de la Mišná 17 אלא המעשה וכל המרבה דברים מביא חטא) / ela hama 'aśé vejol hamarbé debarim mebi het) y su traducción; la Mišná 18; la última Mišná de Macot 3:16 רבי חנניא בן עקשיא אומר) / Rebi Hananiá ben 'Acašya omer) y su traducción.

Capítulo 2 (dos tercios de página y dos páginas):

La primera Mišná, casi hasta el final (לאין אתה בא [לידי עברה]) ve'én atá ba [lidé 'aberá]) y su traducción ('y non tu vinién [a lugar de pecado]'); el final de la Mišná 4 en hebreo (אשנה שמא לא תפנה) / ešné šema lo tipané) y la traducción completa de la Mišná 4; mišnayot 5-6; la Mišná 7, y la traducción hasta קנה לעצמו / caná le 'aṣmó ('compró para sí mesmo').

En la primera hoja del ejemplar, al lado del título de este capítulo, figura la firma del proprietario: די יאודה[!] גואקיל (de Yehudá Guaquil) ${ }^{21}$.

Capítulo 3 (un tercio de página):

Un fragmento descolorido de la traducción de las últimas palabras de la Mišná 18, la última del capítulo ('Rebi Elaźár hi[jo de Hi]smá dićién...; Rebi Hananiá', etc.).

Capítulo 4 (dos tercios de una página y siete páginas):

Mišnayot 1-4; Mišná 5, hasta el final de la traducción, ללא קורדום / veló cordom le'ejol mimena vején ('y non majado para

${ }^{21}$ Encontramos a un R' Elia Guaquil, el cual firma junto con R' Ya'acob Juli, en Constantinopla en 1723. Véase Efraim NABÓN, Mahané Efraim (Constantinopla: Yoná ben Ya'acob, 1738) pág. $7 b$. 
comer de ella y ansi'); Mišná 10, desde el final de la traducción que empieza con 'Rebí Meir dićién'; mišnayot 11-20. En la Mišná 21, solo la Mišná hebrea.

\section{Capítulo 5 (ocho páginas):}

Mišná 1, desde la mitad de la traducción de la Mišná אלא להיפרע / ela lehipará ' min hareša 'ím ('salvo para vengarse de los malos') hasta el final; mišnayot 2-7; Mišná 8, hasta el final de la traducción de la Mišná que empieza con חרב בא לעולם / héreb ba la 'olam ('espada vinién a el mundo'); mišnayot 22-24 (muy descoloridas); Mišná 19 (muy descolorida); Mišná 21, la primera parte de la Mišná hebrea está muy descolorida, pero a partir de בן שלש עשרה לַמְִּוֹ / ben šelóš 'esré lamișvot ('de edad de cinco años para pasuc... de edad de treće para misvot... de edad de ciento como si muriera y pasara del mundo') el texto es claro y la traducción está completa ${ }^{22}$.

Capítulo 6 (dieciséis páginas):

Mišnayot 1-8; Mišná 10, hasta la mitad de la traducción de אברהם א / Abraham quinyán ehad menayin, šene'emar ('Abraham creación una de adonde como ${ }^{23}$ diće [el pasuc]').

22 Este es el orden que aparece al final del capítulo 5; véase más abajo.

23 En la mayor parte del libro, la vocalización indica cumo; al final del mismo hay algunas vocalizaciones de como. 


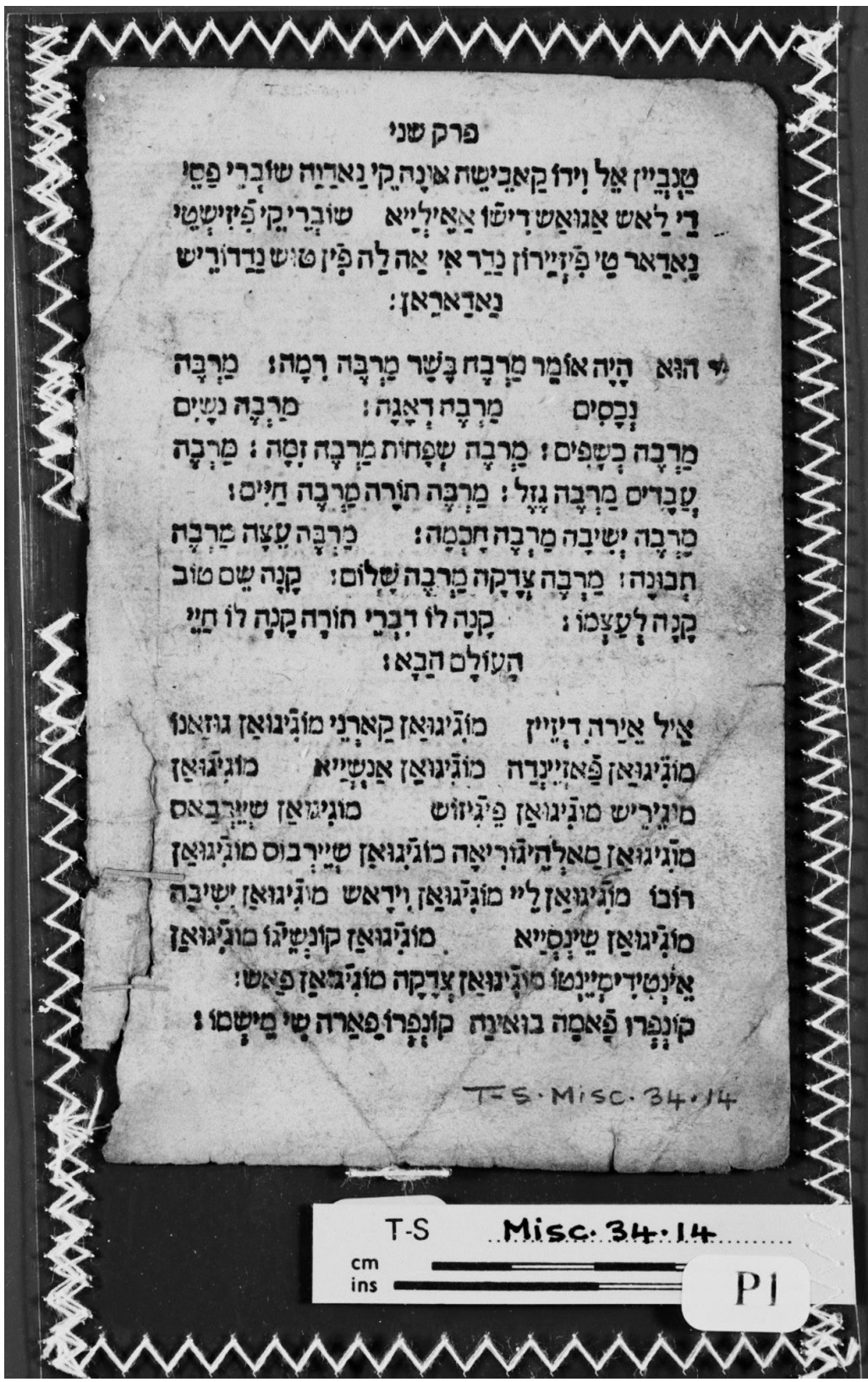

Imagen 1: CUL T-S Misc. 34.14, fol. 1r

(C) 2020. Cambridge University Library 


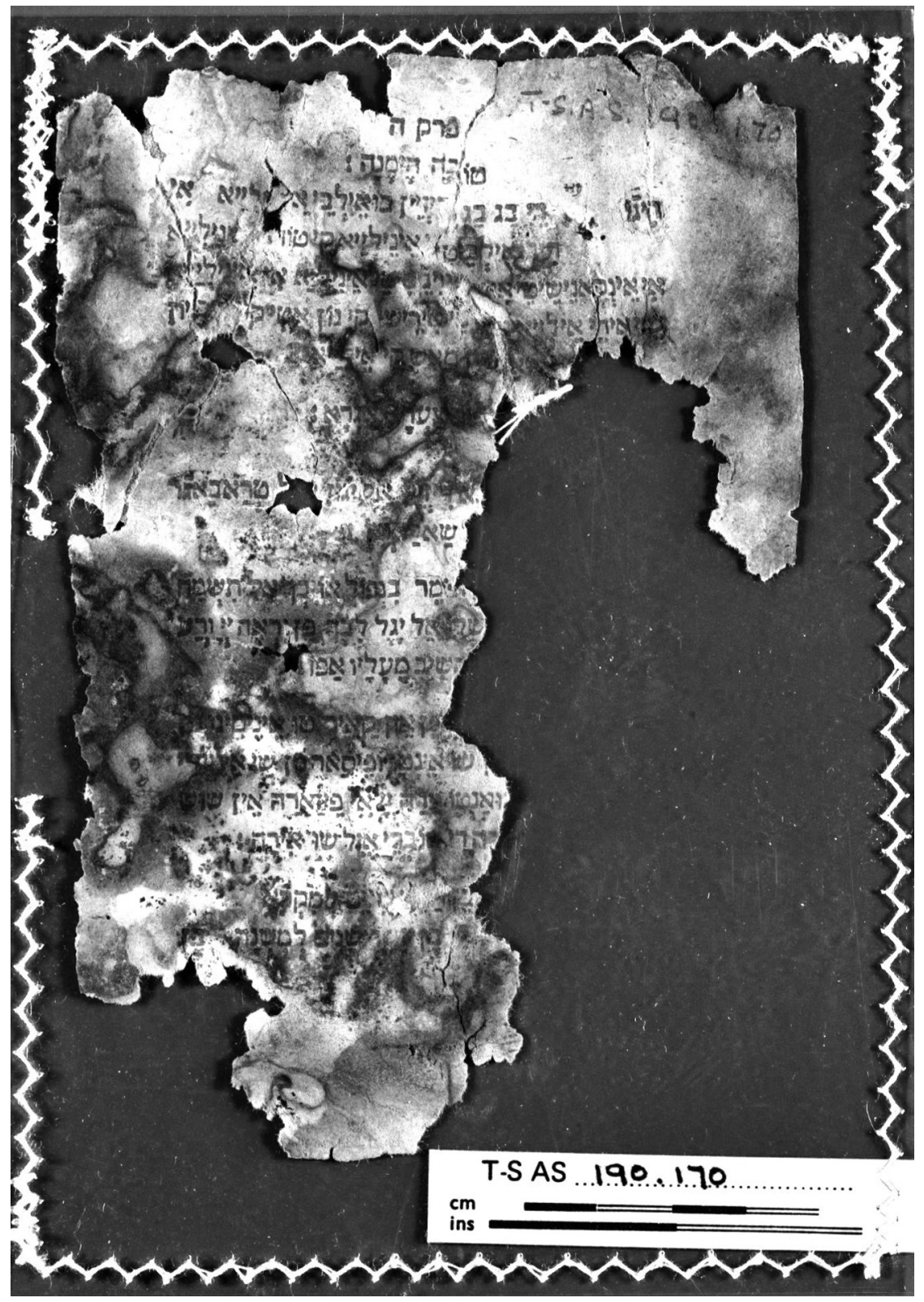

Imagen 2: CUL T-S AS 190.170, fol. 1v

(C) 2019. Cambridge University Library 
2. Comparación entre las versiones de Pirqué Abot de VeneCia de 1601 y de SALÓNICA HaCia 1570

Si bien los fragmentos del texto de esta edición de Pirqué Abot de la Guenizá están incompletos y faltan muchas mišnayot, al comparar la edición de Venecia de 1601 y la de Salónica hacia 1570 se observa que son iguales, a excepción de diferencias muy leves de grafía y muy pocos cambios léxicos. Es evidente que las características especiales de la edición de Venecia de 1601 se encuentran también en la edición de Salónica hacia 1570, tal como se detalla más adelante. A continuación presentaremos dos ejemplos de traducciones idénticas en ambas ediciones:

Ejemplo 1.- Capítulo 2, Mišná 5:

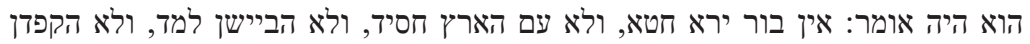

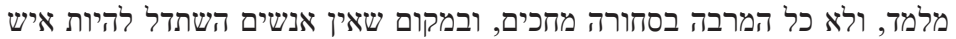

Hu hayá omer: en bur yeré ḥet, veló 'am ha'areș ḥasid, veló habaišán lamed, veló hacapdán melamed, veló kol hamarbé bishorá maḥkim, ubmacom še'én anašim hištadel lihyot iš

Versión en ladino:

Él era dićién: Non el yaćío teme pecado, y no el 'am haareŝ bueno, y no el yergonzośo deprende, y no el escadimośo aveźa, y no todo el que mochigua en mercadería se asabienta; y en lugar que no [h] ay varones percura por ser varón.

Solo en estas dos ediciones se traduce la palabra hebrea בור bur como yaćio; en todas las demás traducciones al ladino se usa la palabra necio. La palabra hebrea מלמד / melamed se traduce como aveźa, de manera similar a las versiones de Ferrara, Ámsterdam y Venecia en caracteres latinos, mientras que en las otras se traduce como enseña o enveźa. La palabra hebrea ביישן / baišán se traduce como yergonzośo > בירגונסוזו> en ambas con la letra bet $>$ ב, aunque en las versiones occidentales se escribe con $v a v\langle 1\rangle \mathrm{o}\langle\mathrm{v}\rangle$, mientras que en las orientales se traduce como vergüenzośo. La expresión لעם הארץ / 'am ha'areș está transliterada también en la versión de Venecia de 1601 y en la de Salónica hacia 1570, y en todas las demás versiones orientales. Las 
traducciones occidentales, a excepción de la que nos ocupa, optan por קפדן iñorante, ignorante, pueblo de la tierra o plebeo. La palabra hebrea / capdán se traduce como escadimośo con dálet $<\uparrow>$, mientras que en todas las versiones en caracteres hebreos aparece escatimośo con tet $<0>$. En caracteres latinos se lee escatimoso, escatimán o escrupuloso. El verbo percurar (correspondiente al hb. להשתדל / lehištadel) se usa, como en otras ediciones de Salónica, en lugar de procurer o precurar.

¿Qué diferencias hay entre ellas? Solo una, en la grafía de la palabra lugar, sin álef para indicar la vocal [a] hacia $1570<$ לוגר>, y con álef en 1601 לוגאר> Todo lo demás es idéntico.

Ejemplo 2.- Capítulo 4, Mišná 11:

רבי אליעזר בן יעקב אומר: העושה מצוה אחת קונה לו פרקליט אחד, והעובר עבירה אחת קונה לו קטיגורי העור אחד. תשובה מצה אחת ומעשים טובים כתריס פרים אחד

בפני הפורענות. - (- בערת

Rebí Eli“ézer ben Ya‘acob omer: ha'osé mișvá aḥat coné lo peraclit ehad, veha'ober 'aberá ahat coné lo categor ehạd. Tešubá uma'asim tobim kitrís bifné hapur'anut.

En ladino:

Rebí Eli ‘ézer dićién: El que haće miŝvá una, compra a él abogador uno; y el que pasa 'aberá una, compra a él contrallador uno. Tešubá y hechas buenas, cochillo delante el daño.

La traducción es idéntica en ambas ediciones. La palabra hebrea / miŝvá se translitera en la traducción como en todas las ediciones orientales; en las occidentales, la traducción es encomendança. También la palabra hebrea עבירה / 'aberá se translitera en la traducción como en todas las ediciones orientales; en las occidentales, la traducción es pecado. La palabra hebrea פרקליט / peraclit se traduce como abogador, como en todas las traducciones en caracteres hebreos, pero en caracteres latinos aparece traducida como procurador. La palabra תשובה / tešubá se translitera en estas traducciones como en todas las ediciones del Imperio otomano, en contraste con las versiones occidentales, que optan por el término contrición. La palabra תריס / terís se traduce solo en estas dos ediciones como cochillo, mientras que las otras se inclinan por los términos escudo, mamparo o adarga. La edición de Venecia de 1601 
incluye en hebreo בן יעקב ben Ya'acob, mientras que en la traducción estas palabras están ausentes. En la edición de Salónica hacia 1570 faltan estas palabras tanto en el original hebreo como en la traducción; aparentemente, en 1601 el tipógrafo agregó los nombres a la versión hebrea apoyándose en otras ediciones conocidas ${ }^{24}$.

No hemos podido comparar con todas las características especiales encontradas en la edición de Venecia de 1601 con la de Salónica hacia 1570, porque faltan muchas mišnayot; no obstante, podemos observar las similitudes entre ellas, no solo en los ejemplos anteriores, sino también en las siguientes características:

a) El orden de las mišnayot al final del capítulo 5 .

A pesar del estado precario de los fragmentos de las hojas de la edición de 1570, se percibe el siguiente orden:

(1) Rebí Yehudá ben Tema omer ('seé desvergonźado como el añamar y liǵero como la águila... desvergonzośo de façes para guehinám...'; Mišná 20 en el texto impreso);

(2) Ben Bag-Bag omer ('yuelve en_ella y revuélvete en_ella...'; Mišná 22 en el texto impreso);

(3) Ben He-He omer ('asegún el trabajo el salario'; Mišná 23 en el texto impreso);

(4) Šemu'el ha-Catán omer ('en caer tu enemigo non te alegres...'; Mišná 19 en el texto impreso);

(5) Hu hayá omer ('de edad de cinco años para pasuc...'; Mišná 21 en el texto impreso).

Encontramos exactamente el mismo orden en la edición de Venecia de 1601. En cambio, en otras ediciones de Pirqué Abot se sigue un orden diferente: 1-3-2-5-4 en Ferrara y Ámsterdam; 1-2-3-5 (sin 4) en Occidente y Jerusalén; 5-1-3-2 (sin 4) en Belgrado y Viena; 1-3-2-5, 1-2-5-3, y 1-5-2-3 ( $\sin 4)$ en varias traducciones de Salónica ${ }^{25}$.

24 Schwarzwald, Translations, pág. 298. Esta corrección se encuentra también en el nombre מתיא בן חרש Matatya (Venecia 1601) / מתתיא Matya ben Haraš (Salónica 1570) en la Mišná 4: 15; cf. Schwarzwald, Translations, págs. 71 y 389, y SHarvit, Language, pág. 165 y Tractate Avoth, pág. 250.

${ }^{25}$ De las 46 ediciones examinadas en la investigación de Schwarzwald, solo en la edición de Venecia de 1601 se encuentra ese orden (Scharzwald, Translations, 
b) Ortografía.

1. En la traducción de la palabra איל / אִילו של אברהם) / éyil šel Abraham 'el carnero de Abraham' 5: 6), בארביץ/baryeŝs en ladino, la edición de Salónica hacia 1570 también incluye la grafía de esta palabra con șade final $\langle\psi\rangle$, al igual que la edición de Venecia de 1601, mientras que todas las demás la escriben con źáyin $<\boldsymbol{\uparrow}>$ o sámej $<\nabla>$, o con $<\mathrm{Z}>$ o $<\mathrm{s}>$ : barbez barvez $/ \mathrm{s}^{26}$.

2. Todas las ediciones traducen מכתב / mijtab (6:2) como escritura, pero en las dos ediciones estudiadas la grafía es אישקריטורא, con álef $<\boldsymbol{K}$-> final en lugar de he $<\mathrm{n}->$.

3. La traducción de גאולה / gue’ulá (6: 6) en ambas ediciones es recmición con cof $\langle p\rangle$, tal y como aparece en las ediciones de Venecia de 1651 y de 1706 en caracteres latinos, mientras que en las otras se traduce de la siguiente manera: remissión en Ferrara y Ámsterdam 1612; redención en ediciones italianas en caracteres hebreos; rehmisión (con het $\langle n>$ ) en las ediciones de Jerusalén y Belgrado, y regmición en todas las demás versiones del Imperio otomano.

c) La traducción de la fórmula שנאמר / šene'emar que introduce la cita de un versículo de la Biblia es: cumo diće el pasuc; mientras que en otras ediciones de Venecia en caracteres hebreos es: como diće el verso, y en las del Imperio otomano es: que ansi diće el pasuc, con el uso de la palabra hebrea pasuc en la traducción. En traducciones posteriores de Florencia, Pisa y Livorno, en caracteres hebreos, aparece: que ansí diće el verso; y en las traducciones en caracteres latinos, como es dicho o que assi es dicho.

d) Los posesivos son nueso/a-s, vueso/a-s, y no muestro/a-s $\sim$ nuestro/a-s o vuestro/a-s como en todas las demás ediciones de Pirqué Abot. El uso de estos posesivos, que es particularmente frecuente también en las bendiciones de Sidur para mujeres de hacia 1565, editado

págs. 78-79). Véase un análisis detallado del orden de las mišnayot al final del capítulo 5 en SHARvit, Language, págs. 214-222.

${ }^{26}$ En CORDE, barves ocurre 6 veces en el Siddur Tefillot de 1492, y barvez una vez en la Biblia de Ferrara. $C f$. Real Academia Española, Banco de datos (CORDE) [en línea]. Corpus diacrónico del español. <http://www.rae.es> [Consultado el 7/7/2019]. 
en la misma imprenta de Yaabets aproximadamente en la misma época, es único en estas versiones ${ }^{27}$.

e) La palabra רְּרִ / rebi está vocalizada en ambas ediciones con ševá y hírec, siguiendo la tradición sefardí, tanto en el original hebreo como en la traducción. La bet está marcada con dag̉éš en la edición de Venecia de 1601, pero no así en la de Salónica hacia 1570.

f) En ambas traducciones es muy frecuente el uso de palabras hebreas en lugares en los que en las otras versiones aparecen palabras españolas. Por ejemplo, גִִּיָָם / guehinam (5: 19), como en las versiones orientales, y guihinán guihinam o infierno en las occidentales; תלמידים / talmidim (6: 5) como en las versiones orientales, en lugar de dicipulos en todas las otras ediciones occidentales; כהונה / kehuná (6: 5) en lugar de sacerdocio en todas las demás versiones occidentales; כהלכה / kahalajá (5: 7) se traduce por como la halajá en lugar de como la razón, como el din, como el derecho en las versiones occidentales; זכו / źejut (6: 1 y 6: 6) en lugar de merecimiento en las otras versiones occidentales; צדקה / Sedacá (2: 7), como en algunas versiones de Viena, Belgrado y Jerusalén, en lugar de justicia o justedad en las otras versiones de Salónica, o caridad, limosna, justedad en las occidentales. A estos ejemplos hay que añadir el uso de palabras hebreas mencionado anteriormente en el Ejemplo 2.

g) La traducción de לכהן גדול / lejohén gadol (5: 5) es a_el kohén grande solo en la edición de Venecia de 1601 y la de Salónica hacia 1570. En las traducciones de Viena, Jerusalén y Belgrado, la traducción es a el kohén gadol; en las otras traducciones de Salónica es a el kohén el grande, y en las occidentales es a el al sacerdote grande.

h) La forma דורות / dorot (5: 2) se traduce como arnaçios solo en la edición de Venecia de 1601 y en todas las versiones de Salónica, incluida la de 1570. Las otras versiones orientales traducen esta palabra

${ }^{27}$ Por ejemplo: Bendicho Tú, YY nueso Dio, Rey de el mundo soltán encarcelados en Birkot hašahar, pág. 16 en el Sidur. En este sidur hay 358 menciones de nueso/s y 719 de nuesa/s, y solo 15 de nuestro/s y 15 de nuestra/s; $c f$. Ora (Rodrigue) ScHWARZWALD, Sidur para mujeres en ladino, Salónica, siglo XVI (Jerusalem: ben Zvi Institute, 2012 [en hebreo y español]). 
como gerenancios, mientras que en las occidentales se traduce como generancios ${ }^{28}$ o siglos.

i) En cuanto al nombre de רבי שמעון בן יהודה / Rebi Šim 'ón ben Yehudá, en las ediciones impresas se menciona a Rebi Šim 'ón ben Menasia (6: 8) ${ }^{29}$, y así aparece este nombre en la Mišná hebrea de la mayoría de las ediciones de Pirqué Abot impresas en caracteres hebreos, excepto en cuatro ediciones orientales y en la de Venecia de 1601, en las que aparece Rebi Šim 'ón ben Yehudá, al igual que en la de Salónica hacia $1570^{30}$. El nombre Yehudá aparece en lugar de Menasia en la mayoría de las traducciones al ladino, al igual que en la edición de Salónica hacia 1570 .

Además de las características ya mencionadas, hay otras que encontramos solo en las ediciones de Venecia de 1601 y de Salónica hacia 1570: להתגדל / lehitgadel (4: 5) se convierte solo en ellas en para engrandecer, sin añadir el pronombre te, mientras que las otras versiones en caracteres hebreos utilizan para por engrandecerte, y las traducciones en caracteres latinos, para te engrandecer. Solo en estas dos versiones se traduce העולם הבא / ha 'olam habá utilizando tanto la expresión el mundo el vinién típica de las versiones orientales (4: 16-17), como la expresión el mundo el venidero típica de las occidentales (4: 1).

Si los fragmentos que pertenecen a la edición de Salónica hacia 1570 estuvieran completos, probablemente habríamos encontrado muchas otras características léxicas similares a las que se hallan en la traducción de Venecia de 1601.

28 En las ediciones de Pisa y Livorno se escribe con het $<n>$ : חיניראסיוניס/ heneraciones.

29 Según Hanoch Albeck (Introduction to the Mishna [Tel Aviv-Jerusalem: The Bialik Institute, 1959 [en hebreo]] pág. 233), tal es el nombre de uno de los últimos tanaítas. En el manuscrito de la Mišná, el nombre habitual es Yehudá y no Menasya; $c f$. SHARvit, Language, págs. 231-232.

30 Schwarzwald, Translations, págs. 72 y 449. 


\subsection{Semejanzas con las versiones occidentales}

En ocasiones, la traducción de las ediciones de Venecia de 1601 y de Salónica de 1570 coinciden con las versiones occidentales. Por ejemplo: ביישן / baišán (2: 5) traducido como yergonzośo tal y como hemos indicado en el Ejemplo 1.

La palabra בריות / beriyot (6:1-2) se traduce como criaturas, como en las versiones occidentales, mientras que las otras versiones la traducen como criaduras o crianzas. La palabra גשמים / guešamim (5: 5) se traduce como lluyias, al igual que en todas las versiones occidentales, mientras que las orientales se inclinan por la variante judeoespañola luvias.

\subsection{Semejanzas con las versiones orientales}

Por otro lado, como ya hemos visto en algunos ejemplos, las ediciones de Venecia de 1601 y de Salónica hacia 1570 coinciden con las versiones orientales y difieren de las versiones occidentales; por ejemplo: גדול gadol (6: 4) se traduce como grande, mientras que todas las demás versiones occidentales lo traducen como mayor. חילול ה' / hillul YY (4:4) se traduce como esyivlamiento de el Criador, mientras que en las versiones occidentales en caracteres hebreos la traducción es profanamiento ayiltamiento del Criador, y en caracteres latinos: profanamiento abiltamiento de nombre del Criador, añadiendo «de nombre».

\section{CONCLUSIÓN}

En la descripción de la edición de Venecia de 1601 Schwarzwald sugiere dos hipótesis:

1. Es posible que la edición de 1601 refleje una antigua tradición medieval, y que esta haya sido la base de las traducciones posteriores conservadas primero en Italia, los Países Bajos y Londres y más tarde 
en todo el Imperio otomano ${ }^{31}$. Prueba de ello es que en la edición de Venecia 1696 el traductor dice explícitamente:

Siendo cierto que la dotrina de estas sentencias es de gran provecho como diće la Guemará, quien quiere seer bueno afirme las palabras de Abot; y par[a] que se entienda bien se tradućió en ladino y agora mudé algunos ladinos más ordinarios, y muchas palabras que estan en LŠH [=lašón hacodeš] las puśe en ladino.

Aparentemente, el traductor cambió algunas palabras en ladino de versiones anteriores por otras más corrientes, es decir, más habituales en la época del traductor, y sustituyó muchas palabras que en las traducciones anteriores estaban en hebreo (lašón hacodeš 'la lengua sagrada') por palabras en ladino. Esto explica la presencia de palabras hebreas en la edición de Venecia de 1601, y su ausencia en las ediciones occidentales posteriores.

2. Es posible que esta fuera una antigua tradición popular basada en la tradición oral que no se mantuvo a lo largo del tiempo, y que se hayan creado otras tradiciones, cuyos principios rectores eran la correspondencia sintáctica con el texto hebreo y el uso de formas gramaticales y léxicas arcaicas.

El descubrimiento de la edición de Salónica hacia 1570, idéntica a la de Venecia de 1601, indica que la de Venecia no es sino una copia de la de Salónica, y que ambas son distintas de las traducciones orientales y occidentales publicadas posteriormente. La diferencia entre estas dos versiones y las ediciones publicadas más adelante en diversos lugares se debe también a la antigüedad de estas traducciones, que conservan características lingüísticas del español antiguo, así como a la distancia geográfica de la publicación de los textos. La conclusión de Schwarzwald, tras haber realizado una comparación lingüística y textual, es que la edición de Venecia es muy similar a las orientales, una afirmación que tiene fundamento: no cabe duda de que se basa en una edición anterior publicada en Salónica, y es posible que hubiera también otras ediciones orientales que hoy por hoy se han perdido.

31 Cf. Schwarzwald, «The Venice 1601 Ladino Translation of Pirke Aboth», págs. 134-135 y 140-142. 
He aquí otro elemento que refuerza esta hipótesis de que la edición de Venecia de 1601 es una copia del texto de Pirqué Abot publicado anteriormente en Salónica, en la imprenta de Giovanni di Gara: en 1602 esta imprenta publicó el libro Šulhán ha-Panim, titulado en ladino Meśa de el alma, una traducción-adaptación de la monumental obra de R. Yosef Caro, Šulhán Aruj. El libro original en ladino fue publicado en Salónica en 1568 por la imprenta de Yaabets. A pesar de que su autor, el rabino Meir Benvenisti ${ }^{32}$, había hecho jurar a sus futuros editores que no editarían el libro en Italia ${ }^{33}$, estos lo publicaron en Venecia. La edición de 1602 fue impresa por Joseph Ben David Franco, que incluyó el prólogo del autor de la primera edición, pero al llegar a las palabras del juramento de no imprimir el libro en Italia, corrigió el texto con un añadido, que no se imprimiera en Italia «sino en Venecia», es decir, a excepción de Venecia ${ }^{34}$.

Al comparar la edición de Salónica de 1568 de Meśa de el alma con la edición de Venecia de 1602 se observa que el libro es una reproducción exacta de la versión de Salónica incluso la extraña grafía de Meśa de el alma de 1568, en la que aparece la letra źayin seguida de yod <i〉 $>$ para representar el fonema $/ 3 /$, se reproduce en la edición de 1602, por

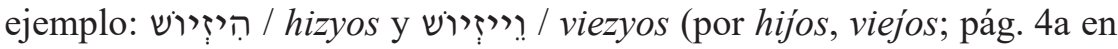
1568; pág. 5b en 1602), מוּזְיָירוּ / muzyer (por mujer; pág. 6b en 1568; pág. 8a en 1602), por dar solo algunos ejemplos.

Por lo tanto, es de suponer que también el Pirqué Abot impreso en Venecia en 1601 es una reproducción exacta de la edición de Salónica

32 Véase la investigación de Dov CoHen, «Who is the author of the Ladino Shulhan ha-Panim (Salonica 1568)?» [en hebreo], Hispania Judaica 11:2 (2015) págs. 33-61.

33 «Y por tanto aconjuro en nombre de Dio Baruj Hu que no haya alguno que lo treslade en letra de goyim, que es gran pecado. Y también no sea que alguno lo quiera estampar en alguna çibdad de Italia, porque allá mudan muchas cośas en nuesas estampas dićiendo que son cuentra de ellos y el que no sabe no pensará que es yerro y yerrará»; cf. Meśa de el alma (1568) págs. 3b-4a de la Introducción.

${ }^{34}$ Cf. Meir Benayahu, Copyright, Authorization and Imprimatour [sic] for Hebrew Books (Jerusalem: Ben Zvi Institute-Harav Kook Institute, 1971 [en hebreo]) págs. 103 y 218-220, y Dov CoHeN, «A Panoramic Survey of Judeo-Spanish Halakhic Books», en Rabbinical Literature in Yiddish and Judezmo, eds. Katja Šmid, Chava TuRniansky y David M. Bunis (en prensa). 
hacia $1570^{35}$. Siendo así, no debe sorprender que las características típicas del Imperio otomano se reprodujeran también en la edición de Venecia de 1601, a pesar de tratarse de una edición italiana. De ahí la importancia del descubrimiento de los fragmentos del tratado Pirqué Abot en la Guenizá, considerados ahora como la edición más antigua que se conoce.

Recibido: $24 / 10 / 2019$

Aceptado: 14/02/2020

35 Benayahu destaca el trabajo de algunos editores originarios de Salónica que publicaron obras en Italia, y especialmente en Venecia. Sobre los contactos entre los judíos de Grecia y de Italia, véase Meir Benayahu, Relations between Greek and Italian Jewry (Tel Aviv: The Diaspora Research Institute, 1980 [en hebreo]) págs. 123-148. 